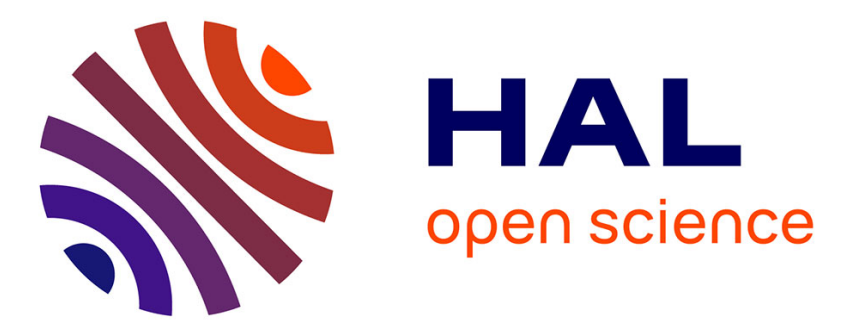

\title{
SERS detection of biomolecules using lithographied nanoparticles towards a reproducible SERS biosensor
}

Catalina David, Nicolas Guillot, Hong Shen, Timothée Toury, Marc Lamy de La Chapelle

\section{- To cite this version:}

Catalina David, Nicolas Guillot, Hong Shen, Timothée Toury, Marc Lamy de La Chapelle. SERS detection of biomolecules using lithographied nanoparticles towards a reproducible SERS biosensor. Nanotechnology, 2010, 21 (47), 10.1088/0957-4484/21/47/475501 . hal-00629337

\section{HAL Id: hal-00629337 https://hal.science/hal-00629337}

Submitted on 5 Oct 2011

HAL is a multi-disciplinary open access archive for the deposit and dissemination of scientific research documents, whether they are published or not. The documents may come from teaching and research institutions in France or abroad, or from public or private research centers.
L'archive ouverte pluridisciplinaire HAL, est destinée au dépôt et à la diffusion de documents scientifiques de niveau recherche, publiés ou non, émanant des établissements d'enseignement et de recherche français ou étrangers, des laboratoires publics ou privés. 


\title{
SERS detection of biomolecules using lithographied
}

\section{nanoparticles towards a reproducible SERS biosensor}

\author{
Catalina David ${ }^{a}$, Nicolas Guillot ${ }^{a}$, Hong Shen ${ }^{b}$, Timothée Toury ${ }^{b}$ and Marc Lamy de la Chapelle ${ }^{a^{*}}$ \\ ${ }^{a}$ Laboratoire CSPBAT (FRE 3043), UFR SMBH, Université Paris XIII, 74 rue Marcel Cachin, 93017 Bobigny, \\ France \\ ${ }^{\mathrm{b}}$ ICD-LNIO-UMR, CNRS 6279, Université de technologie de Troyes, 12 rue Marie Curie, 10010 Troyes, France
}

*Corresponding author: E-mail: marc.lamydelachapelle@univ-paris13.fr

Tel.: (+33) 148387691 


\begin{abstract}
In this paper we highlight the accurate spectral detection of bovine serum albumin and ribonuclease-A using a Surface-Enhanced Raman Scattering (SERS) substrate based on gold nanocylinders obtained by Electron-Beam Lithography (EBL). The nanocylinders have diameter from 100 to $180 \mathrm{~nm}$ with a gap of $200 \mathrm{~nm}$. We demonstrate that optimizing the size and the shape of the lithographied gold nanocylinders, we can obtain SERS spectra of proteins at low concentration. This SERS study enabled us to estimate high enhancement factors $\left(10^{5}\right.$ for BSA and $10^{7}$ for RNase-A) of important bands in the protein Raman spectrum measured for $1 \mathrm{mM}$ concentration. We demonstrate that to reach the highest enhancement it is necessary to optimize the SERS signal and that the main parameter of optimization is the LSPR position. The LSPR have to be suitably located between the laser excitation wavelength which is $632.8 \mathrm{~nm}$ and the position of the considered Raman band. Our study underlines the efficiency of gold nanocylinders arrays in spectral detection of proteins.
\end{abstract}




\section{Introduction}

Surface-enhanced Raman scattering (SERS) is a powerful technique for chemical and biological sensing applications. Widely used for ultrasensitive chemical analysis down to single molecule detection [1-6] its field of applications has been expanded from chemical-biochemical analysis to nanostructure characterization and biomedical applications [7-12].

Based on the excitation of localized surface plasmons (LSP), SERS becomes a very effective tool to analyse molecules, by highly increasing the Raman signals coming from molecules which have been adsorbed on the metal nanosized structures, in particular $\mathrm{Au}, \mathrm{Ag}$ or $\mathrm{Cu}$ [13-19].

Currently most researchers agree on the existence of two processes in the SERS effect: firstly, the enhancement of the local electromagnetic field [20,21] and secondly, the chemical enhancement [22]. The latter enhancement involves the interaction between electronic states of the adsorbed molecule and the surface of the metal. This makes possible a charge transfer between the surface and the adsorbed molecule. This transfer may increase significantly the polarizability of the molecule through the interactions between the electronic states and the metal electrons. However, the dominant contribution to the SERS enhancement is due to the electromagnetic effect ( $10^{12}$ enhancement factor), while the chemical effect contributes to the enhancement only with 2 orders of magnitude. Indeed, when a metallic nanoparticle is irradiated at the resonance frequency of the LSP, its excitation causes a huge enhancement of the local electromagnetic field at the metal particle vicinity and induces an enhancement of Raman signal of the adsorbed molecules [20, 21].

Extensive studies have revealed that the SERS intensity strongly depends on the localized surface plasmon resonance (LSPR) [20, 23-28]. Different papers dedicated to the study of the influence of the LSPR position on SERS intensity demonstrated that, for cylindrical particles, the maximum enhancement must be obtained for a LSPR wavelength located between the laser excitation wavelength and that of the studied Raman mode $[24,26,29]$. However, the enhancement of the observed signal depends on many parameters, including the nature of the metal, the molecule, the type of roughness and the chemical environment.

The SERS effect can be obtained using different metallic substrates like metal island films [2, 30-34], aggregated metal colloids [35, 36], electrochemically roughened electrodes [23] or gold and silver colloidal monolayer [37]. 
In spite of this, due to their complex and irregular structure these substrates often do not lead to uniform, highly sensitive and reproducible SERS effects.

Recent developments in nanofabrication techniques have opened ways to overcome this limitation: Nanosphere Lithography (NSL) [15] and Electron-Beam Lithography (EBL) [24] permit manufacture of reproducible nanostructured surfaces with complex pattern. They provide an exceptional opportunity to engineer controllable SERS substrates.

These techniques enable the fabrication of highly reproducible patterns containing nanoparticles arrays with different geometries, shapes and sizes [38-40]. These parameters can be easily modified thus leading to a spectral shift of the LSPR throughout the visible [26, 40] and IR [41] range. In these conditions, the position of the plasmon resonance can be controlled [42]. With such substrates, the SERS enhancement are important $\left(\sim 10^{5}\right)$ and strongly depend on the nanoparticle coverage and the position of the studied mode with respect to the wavelength of the plasmon resonance [43].

The present paper is dedicated to a systematic study of SERS efficiency at $632.8 \mathrm{~nm}$ excitation wavelength of gold nanocylinders arrays obtained by EBL and having different diameters in order to develop a highly reproducible nanobiosensor. Taking into consideration the lack of SERS studies using these kinds of metallic gratings in the case of biomolecules, the main purpose of our study is to determine the influence of the position of the LSPR on the SERS intensity of proteins.

Since SERS provides important molecular structural information, we carried out SERS spectra of Bovine Serum Albumin (BSA) and bovine pancreatic Ribonuclease A (RNase-A) in order to detect conformational changes and structural differences regarding preferred orientations of molecules with respect to the metal surface [13, 43].

\section{Materials and Methods}

The gold nanocylinders arrays are fabricated on glass substrates by EBL and Lift-off techniques (for more details 40]). The diameters of the nanocylinders range from $100 \mathrm{~nm}$ to $180 \mathrm{~nm}$ while their heights are kept constant to $50 \mathrm{~nm}$, the gratings constant between particles being of $200 \mathrm{~nm}$ (edge to edge). Proteins, BSA and RNase-A, were purchased from Sigma-Aldrich and were used without further purification. All the proteins were prepared at $1 \mathrm{mM}$ concentration in high purity water. The $\mathrm{pH}$ of the aqueous solutions at $22^{\circ} \mathrm{C}$ was 7.0 for $\mathrm{BSA}$ and 8.6 for RNase-A. A drop of each protein was deposited on the SERS substrate until completely dried. The extinction and 
SERS spectra were recorded with a Jobin-Yvon micro-Raman spectrophotometer (Labram 300). The extinction spectra were recorded in transmission configuration with a $10 \mathrm{x}$ objective $(\mathrm{NA}=0.25)$ by removing the edge filters and on an area of $150 \times 150 \mu \mathrm{m}^{2}$ selected by the confocal hole. The sample was illuminated in normal incidence with collimated white light. The SERS spectra were measured using a 100x magnification objective $(\mathrm{NA}=0.90)$ in back scattering geometry, with a spectral resolution of $3 \mathrm{~cm}^{-1}$ and a spatial resolution about $1 \mu \mathrm{m}$. For classical Raman measurements in solution, a macro objective with a focal length of $40 \mathrm{~mm}$ was used $(\mathrm{NA}=$ 0.18). All Raman measurements were carried out with the $632.8 \mathrm{~nm}$ line of a He-Ne laser. The position of the band maxima was reproducible within $\pm 1 \mathrm{~cm}^{-1}$. The laser equivalent power density was $1350 \mathrm{Wm}^{-2}$ for SERS measurements.

\section{Results and Discussion}

\section{SERS measurements}

Our SERS measurements were performed for both proteins BSA and RNase-A. Albumins are the most abundant proteins in blood plasma and they act as transport protein for numerous endogenous and exogenous compounds [44]. BSA is an albumin with a $66.4 \mathrm{kDa}$ molecular weight and its structure is composed of 583 amino acids. The secondary structure of this protein is for the most part helical (70\%) [45].

The structure of RNase-A, which plays an important role in the hydrolysis of RNA is more stable than that of the BSA. It contains 124 amino acids $(13.7 \mathrm{kDa})$ whose spatial arrangement describes two types of secondary structure: $\alpha$-helix and $\beta$-sheet.

The vibrational spectrum of BSA was revealed by both classical Raman [46, 47] and SERS spectroscopy [19, 48] long time ago by different research teams. The spectral assignment of this protein is well known, as well for RNase-A which has been studied extensively by Raman [49, 50] and SERS spectroscopy [19].

In the figure 1, we present the SERS spectra measured for BSA and RNase-A at $1 \mathrm{mM}$ in aqueous solution concentration using the lithographied gold nanocylinders as SERS substrate. 

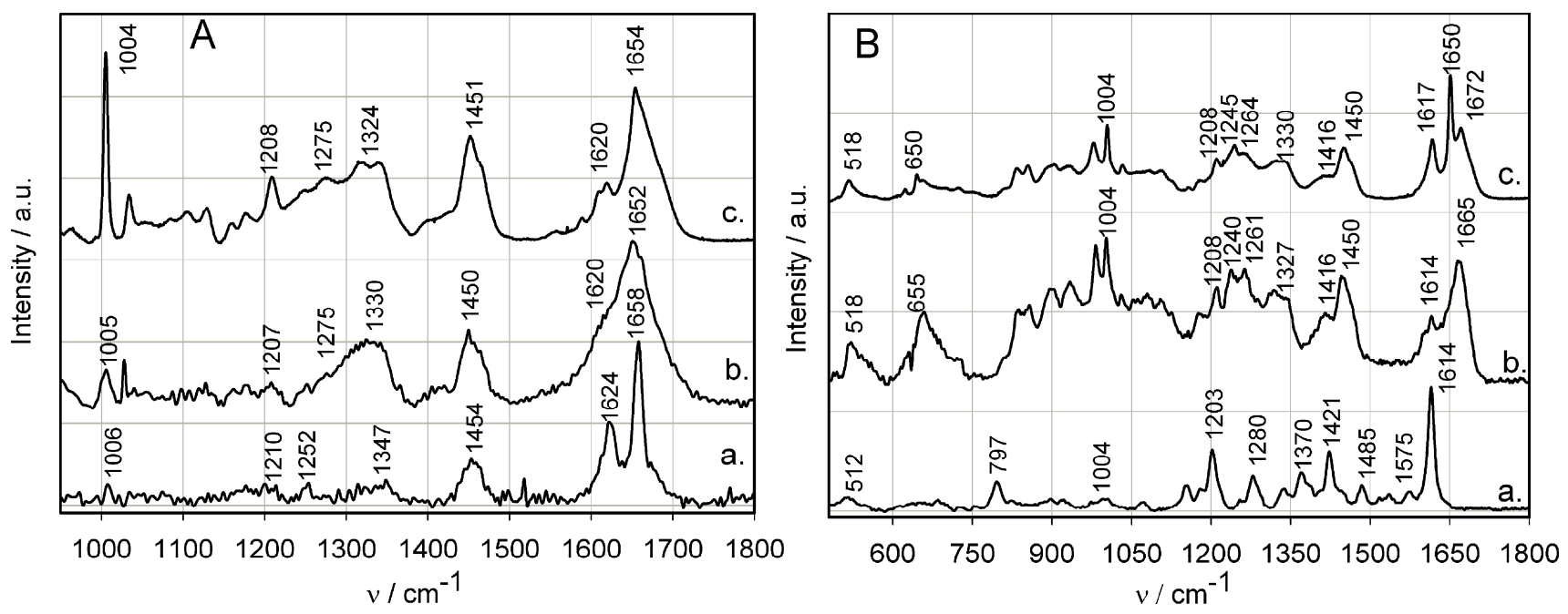

Figure 1. A) SERS spectrum measured for BSA at $1 \mathrm{mM}$ concentration (a.) with acquisition time of 100s: comparison with the Raman spectra of BSA in aqueous solution at $1 \mathrm{mM}$ (b.) and in powder state (c.). The intensities were normalized with respect to the intensity of the band located at $1658 \mathrm{~cm}^{-1}$. B) SERS spectrum measured for RNase-A at $1 \mathrm{mM}$ concentration (a.) with acquisition time of 20s: comparison with the Raman spectra of RNase-A in aqueous solution at $1 \mathrm{mM}$ (b.) and in powder state (c.). The intensities were normalized with respect to the intensity of the highest band located between 1600 and $1700 \mathrm{~cm}^{-1}$.

If comparing the SERS spectrum of BSA (figure 1A(a.)) with classical Raman spectrum of BSA in powder state (figure $1 \mathrm{~A}(\mathrm{c}$.$) ) or in aqueous solution at 1 \mathrm{mM}$ concentration (figure $1 \mathrm{~A}(\mathrm{~b}$.$) ), one can note that the protein$ adsorption directly on the nanocylinders arrays does not seem to induce important conformational changes in its structure. In the SERS spectrum, we can easily identify the amide I band $\left(1658 \mathrm{~cm}^{-1}\right)$, the protein side chain deformation $\left(1453 \mathrm{~cm}^{-1}\right)$ or even the contribution of the disordered $\alpha$-helix structure of the BSA in the amide III band $\left(1252 \mathrm{~cm}^{-1}\right)$.

On the other hand, the deposition of one drop of RNase-A in aqueous solution at $1 \mathrm{mM}$ concentration, on the gold nanocylinders arrays leads to strong conformational changes of the protein structure. This behaviour is observed when we compare the SERS spectrum (figure 1B(a.)) with the classical Raman spectra in powder state (figure 1B(c.)) or aqueous solution of the RNase-A (figure 1B(b.)). The lack of the amide band (around $1665 \mathrm{~cm}^{-1}$ ) in the SERS spectrum strongly indicates that there is a significant change in the secondary structure of RNase-A. 
It has been shown that the vibrational bands of the aromatic amino acids are sensitive to the microenvironment upon protein folding/unfolding process [51-53]. Obviously, the conformational change of RNase-A is highlighted by the presence in the SERS spectrum of strong enhanced vibrational bands specific to the different aromatic amino acids vibrations (Trp and Phe bands located at $1614 \mathrm{~cm}^{-1}, 1370 \mathrm{~cm}^{-1}, 1203 \mathrm{~cm}^{-1}$ and $797 \mathrm{~cm}^{-1}$ ).

From another point of view, if we look closely the SERS spectra, we can observe that the enhancement of the Raman signal varies as a function of the diameters of the nanoparticles. For a detailed analysis, we represented the SERS intensity of one specific Raman band for each protein as a function of nanocylinders diameters (figures $2 \mathrm{a}$ and $2 \mathrm{~b}$.). The considered Raman bands for BSA are the amide I band located at $1658 \mathrm{~cm}^{-1}$ and at $1624 \mathrm{~cm}^{-1}$ and for RNase-A the considered Raman band is that located at $1614 \mathrm{~cm}^{-1}$ assigned to Trp and Phe ring vibrations. The SERS intensity is estimated from the fit of the Raman bands using Lorentz function.
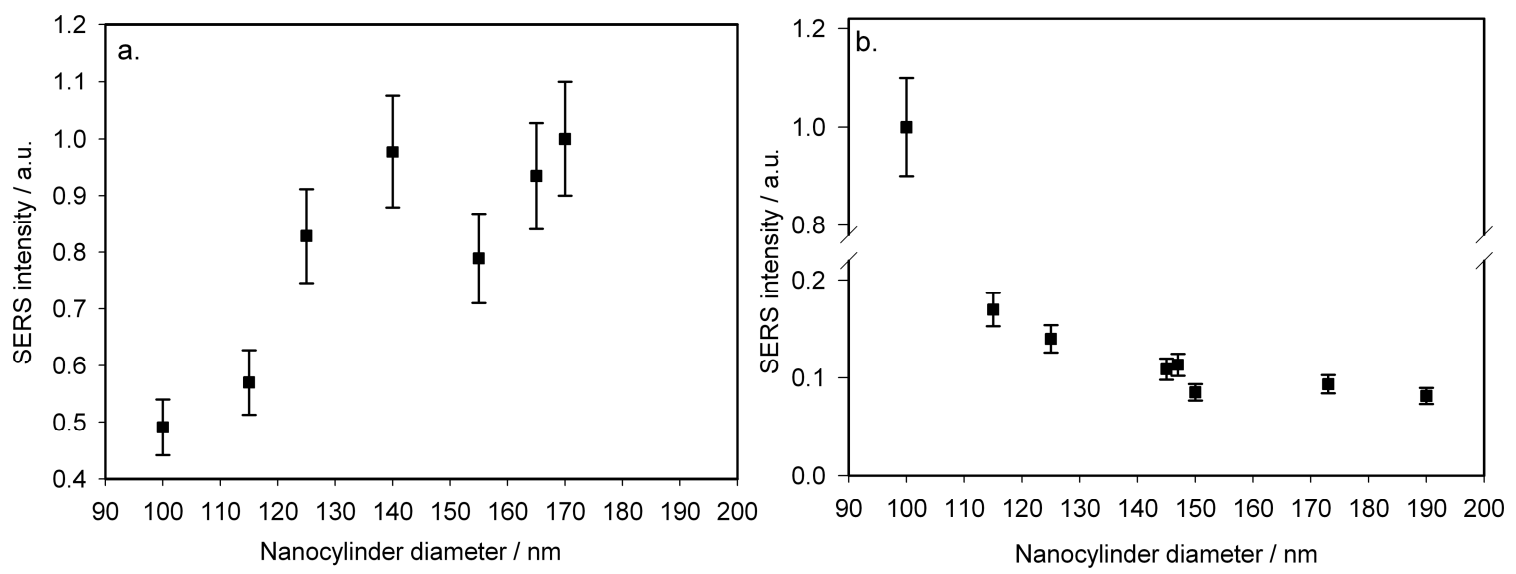

Figure 2. SERS intensity as a function of the nanocylinder diameters: (a) for the BSA Raman bands located at 1614 and $1658 \mathrm{~cm}^{-1}$ and (b) for the RNase-A Raman band located at $1614 \mathrm{~cm}^{-1}$. In order to make more readable the errors bars in figure 2(b) we applied a break on the $\mathrm{Y}$ axis (between 0.22 and 0.78 )

The figure 2 shows that the maximum SERS intensity for BSA (figure 2(a)) is obtained in the case of the nanocylinder having the diameter of about $170 \mathrm{~nm}$ while for RNase-A (figure 2(b)) this diameter is about 100 nm.

\section{Estimation of the enhancement factor}

We have estimated the enhancement factor of the Raman signal of the amide I band of BSA $\left(1658 \mathrm{~cm}^{-1}\right)$. For this, we have determined the number of molecules excited by the laser beam in the case of two types of 
measures of BSA at $1 \mathrm{mM}$ concentration: classical Raman in aqueous solution and SERS on gold nanocylinders. The enhancement factor per molecule is defined as [24]:

$$
G=\left(\frac{N_{2}}{N_{1}}\right)\left(\frac{I_{\text {SERS }}}{I_{r e f}}\right)
$$

Here $\mathrm{N}_{2}$ represents the number of molecules excited within the volume of the laser waist for the BSA solution at $1 \mathrm{mM}$ and $\mathrm{N}_{1}$ is the number of molecules contained in the monolayer deposited on gold substrate illuminated by the laser spot. The term I IERS is the intensity of the BSA Raman amide I bands recorded on the gold nanoparticles while the $I_{\text {ref }}$ is the intensity of the same bands in the BSA spectrum measured in aqueous solution for a concentration of $1 \mathrm{mM}$.

In the case of gold nanocylinders having a diameter around $170 \mathrm{~nm}$ the collection area is about $1.5 \times 10^{-10} \mathrm{~m}^{2}$ for a pattern that contains 6656 nanocylinders. Taking into account the fact that the surface of one BSA molecule is about $40 \times 10^{-18} \mathrm{~m}^{2}$ and assuming that there is a single monolayer of absorbed molecules, $\mathrm{N}_{1}$ is found to be approximately $3.75 \times 10^{6}$ molecules on the nanocylinder array.

$\mathrm{N}_{2}$ was estimated from the volume of the laser waist which is approximated to a cylinder with a radius of $150 \mu \mathrm{m}$ and a depth in the sample of $10 \mathrm{~mm}$. The calculated volume is about $7 \times 10^{-10} \mathrm{~m}^{3}\left(7 \times 10^{-7} \mathrm{~L}\right)$, thus leading to a $\mathrm{N}_{2}$ value of approximately $4 \times 10^{12}$ molecules. According to the formula 1 , the enhancement factor for the BSA Raman band located at $1658 \mathrm{~cm}^{-1}$ is found to be about $10^{5}$.

In the case of RNase-A, we have also estimated an enhancement factor for the vibrational band located at 1614 $\mathrm{cm}^{-1}$ in the SERS spectrum. Following the same approach as previously, we found that the collection area is about $8 \times 10^{-12} \mathrm{~m}^{2}$ and contains $10^{12}$ nanocyliders with a diameter of $100 \mathrm{~nm}$ each. Taking into account that the surface of one RNase-A molecule is $6.0 \times 10^{-18} \mathrm{~m}^{2}$, the number of RNase-A molecules $\left(\mathrm{N}_{1}\right)$ covering the collection area is about $1.33 \times 10^{6}$.

Replacing data in equation 1 , one can obtain the estimated enhancement factor for the band located at $1614 \mathrm{~cm}^{-1}$ in the SERS spectra of RNase-A which is of about $10^{7}$.

The estimated values for the enhancement factor are coherent with those proposed in literature [24] and show the efficiency of gold nanocylinders in the case of proteins.

Comparing the SERS spectra of the two proteins with theirs Raman spectra in aqueous solution (as shown in figure 1), we noted that the degradation of the secondary structure of the protein when reacting with the metal 
surface could give rise to strong Raman enhancement of some aromatic acids from the protein structure. This fact underlines that the Raman cross-sections of the studied modes of these proteins remain the same and the SERS effect occurs rather from the enhancement of the local electromagnetic field. Nevertheless, the conformational changes of the protein when deposited on the metallic surface may be overcome by employing the functionalization of the surface e.g. using antibodies or other intermediate molecules.

\section{SERS optimization: LSPR characterization}

When varying shape, size and distance between the nanoparticles, LSPR positions are shifted to a large extent over the visible spectrum [24, 29], therefore we investigated the relation between the position of the LSPR and the Raman enhancement in order to optimize the SERS signal and to use the substrate as biosensor chip.

In order to find the exact LSPR wavelength to maximize the SERS intensity, we first measured the extinction spectra for each nanocylinder array. At first sight, these spectra (figures $3 \mathrm{a}$ and $3 \mathrm{~b}$ ) strongly suggest that the protein deposition on the nanocylinders leads to a red shift of the LSPR if compared to the position of the plasmon resonance measured in the presence of air.
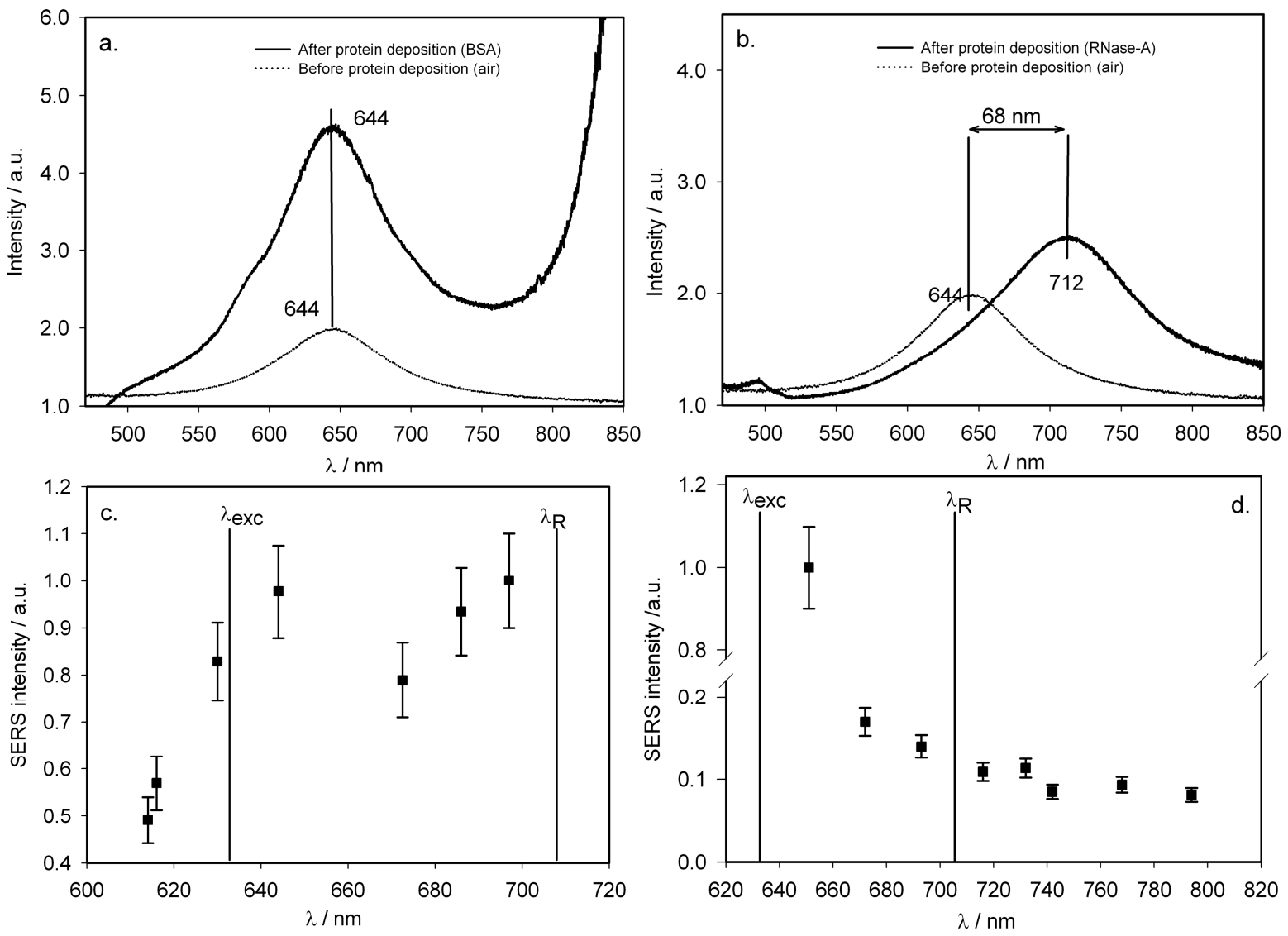
Figure 3. Extinction spectra measured for BSA (a) and RNase-A (b) in the case of nanocylinder arrays with a diameter of $140 \mathrm{~nm}$, showing the shift of the position of the plasmon resonance due to the protein deposition on the nanoparticles with respect to the air. SERS intensity as a function of the position of the plasmon resonance calculated for the BSA Raman bands located at 1614 and $1658 \mathrm{~cm}^{-1}$ (c) and the RNase-A Raman bands located at $1614 \mathrm{~cm}^{-1}(\mathrm{~d})$. The excitation wavelength, $\left(\lambda_{\text {exc }}\right)$ is $632.8 \mathrm{~nm}$ and the considered Raman band $\left(\lambda_{\mathrm{R}}\right)$ for BSA is located at $707 \mathrm{~nm}$ and for RNase-A at $705 \mathrm{~nm}$. In order to make more readable the errors bars in figure 3(d) we applied a break on the $\mathrm{Y}$ axis (between 0.22 and 0.78 )

The red shift of the LSPR for RNase-A is about $68 \mathrm{~nm}$ (figure 3(b)) whereas the one in the case of BSA is almost zero with respect to the air (figure 3(a)). The BSA is a larger protein than the RNase-A. We should then assume that the deposition of the BSA at the nanocylinder surface leads to a larger change in the dielectric constant of the surrounding medium and thus should lead to a larger red shift of the LSPR. Since it does not correspond to our observation, we suggest that the dipolar mode is shifted in the near infra-red spectral range and that the observed LSPR corresponds to the third order of resonance. This is confirmed by the observation of an increase of the extinction intensity for a wavelength higher than $800 \mathrm{~nm}$. We assume that this increase corresponds to the high frequency side of the dipolar LSPR. In this latter case, the dipolar LSPR should be located close to $950 \mathrm{~nm}$ corresponding to a shift around $250 \mathrm{~nm}$. Since the 3rd order of resonance of nanocylinders gives lower enhancement than the dipolar one [28], this observation can also explain the lower enhancement factor measured for BSA compared to RNase-A.

However to go further in our analysis, we plotted the SERS intensity as a function of LSPR position, for both proteins as shown in the figures 3(c) and 3(d). Whatever the protein is, one can observe that the maximum enhancement is obtained for a LSPR wavelength located between the laser excitation wavelength and that of the studied Raman mode (that of $1658 \mathrm{~cm}^{-1}$ for BSA and of $1614 \mathrm{~cm}^{-1}$ for RNase-A). However, due to the LSPR shift towards the 3rd order of resonance, there is not a real maximum enhancement in the case of the BSA. These results provide evidence that the optimization of the gold nanocylinders size is required in order to obtain a high 
enhancement factors and a better sensitivity. Indeed, our study is encouraging but it is obviously that it is necessary to continue with further experiments to improve at the same time the enhancement of the Raman signals of proteins and the detection limit. We saw that the SERS efficiency of these substrates is different from one protein to another and the SERS experience on biomolecules should take into account this consideration. It is not obviously that increasing the nanocylinder diameter it will lead to a better enhancement of the Raman signals. Contrary, the position of resonance of the plasmon plays a very important role in the SERS activity. Indeed, as shown on figure 3, the optimisation should not be done on the geometrical parameters of the nanocylinders but on their optical properties since in both cases, we get the best SERS signal for a LSPR position located between the excitation wavelength and the Raman mode.

On the other hand, throughout this study we demonstrate that by using the gold nanocylinders arrays obtained by EBL method it is possible to measure SERS spectra of BSA and RNase-A. In order to estimate the potential sensitivity of such substrate, let us discuss on the signal-to-noise ratio obtained with our Raman set-up. For BSA, this ratio is around 10 whereas it is around 60 for RNase-A. Thus, with such ratio, we assume that lower concentration of proteins can be detected with our SERS substrate. A limit of detection (LOD) can be estimated to be close to $10^{-4} \mathrm{M}$ for BSA and between $10^{-4}$ and $10^{-5} \mathrm{M}$ for RNase-A. These LOD are not very low but it is known that cylinders are not the most efficient nanoparticles to reach the highest enhancement factor. Thus, using other structures such nanowires or coupled nanoparticles using EBL, we could decrease these LOD and increase the sensitivity of our SERS substrate. These reproducible SERS substrates can actually be used to develop a highly sensitive nanosensor chip for pathogen biosensor applications.

\section{Conclusion}

In this study, we have demonstrated that the lithographied gold nanocylinders obtained by EBL technique, provide SERS spectra of bovine serum albumin and ribonuclease-A at $1 \mathrm{mM}$ concentration in aqueous solution. The reproducibility of the SERS substrate and thus of the SERS spectra of proteins can help us to better understand the origin of the SERS mechanism and to correlate its effects with the Raman intensity enhancement as shown in this paper. The gold nanocylinders are good candidates to reveal a significant SERS effect for proteins at $1 \mathrm{mM}$ concentration, with a gain per molecule of about $10^{5}$ for BSA and $10^{7}$ for RNase-A. This SERS 
effect depends in a critical manner on the position of the Raman band maximum relatively to the plasmon resonance wavelength. On the other hand, we have clearly proved that the Raman gain rises to a maximum when the LSP resonance wavelength is located between the laser excitation wavelength and that of the studied Raman mode.

Our results strongly suggest that these nanoparticles could be used to manufacture a highly reproducible SERS sensor. In order to determine the sensitivity of this SERS substrate, we have estimated the detection limit for these two proteins in the same experimental conditions (around $10^{-4}$ and $10^{-5}$ for BSA and RNase-A respectively). Greater sensitivity and a high molecular specificity could be reached by a high control and optimization of the sensor parameters: the nanoparticles geometrical parameters, their optical properties, their enhancement factor, their functionalisation... With such control, it is possible to reach a high level of reproducibility on the selectivity and the sensitivity of our sensor and on its main characteristics.

\section{Acknowledgements}

This work has been supported by FP7-HEALTH-F5-2009-241818 - NANOANTENNA European project and the Conseil Régional de Champagne Ardenne.

\section{References}

[1]. Kneipp, K., Wang, Y., Kneipp, H., Perelman, L.T., Itzkan, I., Dasari, R.R., Feld, M.S., 1997, Phys. Rev. Lett, 78, 1667-1670.

[2]. Constatino, C.J.L., Lemma, T., Antunes, P.A., Aroca, A, 2001, Anal. Chem, 73, 3674.

[3]. Le Ru, E.C., Etchegoin, P.G., Meyer, M., 2006, J. Chem.Phys., 125, 204701.

[4]. Otto, A., 2006, J. Raman Spectrosc., 37, 937.

[5]. Blackie, E.J., Le Ru, E.C., Meyer, M., Timmer, M., Burkett, B., Northcote, P., Etchegoin, P.G., 2008, Phys. Chem. Chem. Phys., 10, 4147-4153. 
[6]. Blackie, E.J., Le Ru, E.C., Etchegoin, P.G., 2009, J. Am. Chem. Soc., 131, 14466-14472.

[7]. Hu, J., Sheng, R.S., San Xu, Z., Zeng, Y., 1995, Spectrochimica Acta, 51A (6), 1087-1096.

[8]. Aroca, R., 2006, Surface-Enhanced Vibrational Spectroscopy, John Wiley \& Sons Ltd: Chichester, UK, 141176.

[9]. Kneipp, K., Moskovits, M., Kneipp, H., 2006, Eds., Surface-Enhanced Raman Scattering: Physics and Applications, Springer, Berlin.

[10]. Lacharmoise, P.D., Le Ru, E.C., Etchegoin, P.G., 2008, ACS Nano, 3(1), 66-72.

[11]. Iosin, M., Toderas, F., Baldeck, P.L., Astilean, S., 2009, J. Molec. Struct., 924-926, 196-200.

[12]. Hudson, S.D., Chumanov, G., 2009, Anal. Bioanal. Chem., 394, 679-686.

[13]. Shafer-Peltier, K.E., Haynes, C.L., Glucksberg, M.R., Van Duyne, R.P., 2003, J. Am. Chem. Soc., 125, 588593.

[14]. Xu, S., Ji, X., Xu, W., Zhao, B., Duo, X., Bai, Y., Ozaki, Y., 2005, J. Biomed. Optics, 10 (3), 031112.

[15]. Zhang, X., Shah, N.C., Van Duyne, R.P., 2006, Vibr. Spectr., 42(2), 2006.

[16]. Douglas, P., Stokes, R.J., Graham, D., Smith, W.E., 2008, Analyst, 133, 791.

[17]. Qian, X., Peng, X.H., Ansari, D., Yin-Goen, Q., Chen, G.Z., Shin, D.M., Yang, L., Young, A.N., Wang, M.D., Nie, S., 2008, Nat. Biotech., 26, 83-90.

[18]. Stokes, R.J., McBride, E., Wilson, G.C., Girkin, J.M., Smith, W.E., Graham, D., 2008, Appl. Spectroscopy, 62(4), 371.

[19]. Das, G., Mercarini, F., Gentille, F., De Angelis, F., Kumar HG, M., Candeloro, P., Liberale, C., Cuda, G., Di Fabrizio, E., 2009, Biosensor and Bioelectronics, 24, 1693-1699.

[20]. Haynes, C.L., McFarland, A.D., Van Duyne, R.P., 2005, Anal. Chem., A, 77, 339-346

[21]. Le Ru, E.C., Meyer, M., Blackie, E., Etchegoin, P.G., 2008, J. Raman Spectr., 39, 1127-1134. 
[22]. Otto, A., 2001, Phys. stat. sol., 188(4): 1455-1470.

[23]. Jeanmaire, D.L., Van Duyne, R.P., 1977, J. Electranal. Chem., 84, 1.

[24]. Félidj, N., Aubard, J., Levi, G., 2002, Phys. Rev. B, 65, 075419.

[25]. Yonzon, C.R., Zhang, X., Van Duyne, R.P., 2003, Proc. of SPIE, 5224.

[26]. Grand, J., Lamy de la Chapelle, M., Bijeon, J.L., Adam, P.-M., Vial, A., Royer, P., 2005, Phys. Rev. B, 72 , 33407.

[27]. Billot, L., Lamy de la Chapelle, Grimault, A.-S., Vial, A., Barchiesi, D., Bijeon, J.-L., Adam, P.-M., Royer, P., 2006, Chem. Phys. Lett., 422, 303-307

[28]. Guillot, N., Shen, H., Frémaux, B., Peron, O., Rinnert, E., Toury, T., Lamy de la Chapelle, M., 2010, Appl. Phys. Lett., 97, 1-3.

[29]. Félidj, N., Aubard, J., Levi, G., 2003, Appl. phys. lett, 82(18), 3095-3097.

[30]. Liao, P.F., 1982, In: Surfaced-Enhanced Raman Scattering, Eds., Chang, K.R., Furtak, T.A., Plenum New York, 315 .

[31]. Bingler, H.G., Brunner, H., Leitner, A., Aussenegg, F.R., Wokaun, F., 1995, Mol. Phys., 85, 587.

[32]. Kahl, M., Voges, E., 2000, Phys. Rev. B, 61, 14078.

[33]. Weitz, D.A., Garoff, S., Gersten, J.I., Nitzan, A., 1983, J. Chem. Phys., 79, 5324.

[34]. Goudonnet, J.P., Bijeon, L.J., Warmark, R.J., Ferrel, T.L., 1991, Phys. Rev. B, 43, 4605.

[35]. Creighton, J.A., Blatchford, C.G., Albrecht, M.G., 1980, J. Chem. Soc., Faraday Trans. 2, 75, 790.

[36]. Keating, C.D., Kovalevski, K.M., Natan, M.J., 1998, J. Phys. Chem. B, 102, 9404-9413.

[37]. Freeman, R.G., Garbar, K.C., Allison, K.J., Bright, R.M., Davis, J.A., Guthrie, A.P., Hommer, M.B., Jackson, M.A., Smith, P.C., Walker, D.G., Natan, M.J., 1995, Science, 267, 1629.

[38]. Gotschy, N.W., Vonmetz, K., Leitner, A., Aussenegg, F.R., 1996, Opt. Lett., 21, 1099. 
[39]. Salerno. M., Félidj, N., Krenn, J.R., Leitner, A, Aussenegg, F.R., 2001, Phys. Rev. B, 63, 165422.

[40]. Grand, J., Koskcheev, S., Bijeon, J.L., Lamy de la Chapelle, M., Adam, P.M., Rumyantseva, A., Lérondel, G., Royer, P., 2003, Synthetic Metals, 139, 621-624.

[41]. Neubrech, F., Kolb, T., Lovrincic, R., Fahsold, G., Aizpurua, J., Toimil-Molares, M.E., Karim, S., Cornelius, T.W., Neumann, R., Pucci, A., 2006, Appl. Phys. Lett., 89, 253104.

[42]. Grand, J., Adam, P.-M., Grimault, A.-S., Vial, A., Lamy de la Chapelle, M., Bijeon, J.-L., Kostcheev, S., et Royer, P., 2006, Plasmonics, 1(2), 135-140.

[43]. Li, X.L., Xu, W.Q., Zhang, J.H., Jia, H.Y., Yang, B., Zhao, B., Li, B.F., Ozaki, Y., 2004, Langmuir, 20 , 1298-1304.

[44]. Nakamura, K., Era, S., Ozaki, Y., Sogami, M., Hayashi, T., Murakami, T., 1997, FEBS Lett., 417, $375-$ 378.

[45]. Sugio, S., Kashima, A., Mochizuki, S., Noda, M., Kobayashi, K., 1999, Protein Eng., 12, 439-446.

[46]. Chen, M.C., Lord, R.C., 1976, J. Am. Chem. Soc., 98, 990-992.

[47]. Liang, M., Chen, V.Y.T., Chen, H-L., Chen, W., 2006, Talanta, 69, 1269-1277.

[48]. Cavalu, S., Cinta-Pinzaru, S., Leopold, N., Kiefer, W., 2001, Biopolymers, 62(6), 341-348.

[49]. Yu, N.T., Jo, B.H., Liu, C.S., 1972, J. Am. Chem. Soc., 94, 7572

[50]. Koenig, J.L., Frushour, B.G., 2004, Biopolymers, 11(12), 2505-2520.

[51]. Siamwiza, M.N., Lord, R.C., Chen, M.C., Takamatsu, T., Harada, I., Matsuura, H., Shimanouchi, T., 1975, Biochemistry, 14, 4870-4876.

[52]. Van Dael, H., Lafaut, J.P., Van Cauwelaert, F., 1987, Eur. Biophys. J., 14, 409-414.

[53]. Jenkins, A.L., Larsen, R.A., Williams, T.B., 2005, Spectrochim. Acta Part A, 61, 1585-1594. 